\title{
Study on the Purpose, Significance and Pattern of Chinese Traditional Sports Culture Teaching for Foreign Students
}

\author{
Fangyan Yang ${ }^{1, a}$ \\ ${ }^{1}$ Changsha Medical University, Changsha, Hunan, 410219
}

\begin{abstract}
Keywords: Foreign Students, Chinese Traditional Sports Culture, Teaching Purpose
\end{abstract}
\begin{abstract}
Chinese traditional sports culture has a high influence in the international community, such as martial arts, tai chi, etc., most students also expressed a strong interest in it (therefore, we rational use of physical education or sports competitions and other ways to It is of great significance for Chinese students to carry on traditional Chinese sports culture education, and it will also have important theoretical and practical significance for the research and discussion in this field.
\end{abstract}

\section{Introduction}

With the continuous development of national strength, the status of the international community has become increasingly prominent in the international exchanges which also have a higher voice, so many foreign countries aspire to. In recent decades, especially in China in the international Olympic Games, the athletes achieved excellent results and attracting foreign students continue to come to China, to learn the splendid culture of the motherland and conservation of moral character. China's traditional sports and cultural education is favored by foreign students. China's traditional sports refers to China's 5,000 years of long history of heritage development, benefit from human health, longevity of physical exercise methods, with the continuous development and progress of society, each period, different nationalities have formed their own traditional knowledge of sports culture. The traditional sports culture education is the baptism of time and the precipitation of history, contains the essence of the ancient literati mind, more worthy of people to learn and understand.

\section{The Significance of Developing Traditional Sports Culture Education in Chinese College Students}

University is an important channel for the transmission and popularization of national traditional sports culture. It is one of the important cultural forms of colleges and universities and is a valuable national traditional cultural resource. The development of traditional physical education teaching not only greatly expanded and enriched the contents of physical education in colleges and universities, but also brought the traditional culture of the Chinese nation to be inherited and developed. At the same time, it could also add vitality to the development of college sports and campus sports, Development to create favorable conditions. For example, martial arts is the essence of Chinese traditional culture, it combines the traditional Chinese philosophy, traditional medicine, ethics, traditional health, aesthetics, military and other cultural ideas and traditional ideas, with Western sports cannot match the value characteristics. Thus, in the promotion of physical education curriculum reform and should pay attention to the important role of traditional sports, as an important curriculum resources to introduce the classroom. For example, dragon boat culture is not only one of the important contents of the traditional culture of the Chinese nation, but also a precious legacy of traditional national sports culture. The dragon boat race has a history of thousands of years and it is all over the south of the Yangtze River. In the vast national traditional culture atmosphere, the same dragon boat races have different national unique meaning and style dragon boat culture. With the continuous progress of society, dragon boat culture has gradually moved to the road of modern development, reflecting the social characteristics of traditional sports. It is very important to set up traditional national sports courses for international students in the general comprehensive institutions, and it is an important way to spread the traditional Chinese culture. First of all, the major colleges and universities, talent, with students from around the world 
resources for the Chinese culture to the world to provide an important condition. Secondly, on the other hand, the understanding of traditional Chinese sports culture and the participation of traditional sports can make the students better understand the cultural characteristics and development of the Chinese nation, so that students can better integrate into the study abroad. Finally, through the "opening of the traditional national sports curriculum" platform, to strengthen the exchange of physical education between colleges and universities to promote the traditional colleges and universities traditional sports education continue to move forward.

\section{The Purpose of Chinese Traditional Sports Culture Education for Foreign Students}

In the teaching curriculum of our country, the curriculum education of foreign students is an important part of the national teaching curriculum. It is an important way to spread the national cultural traditions, humanistic literacy and expand the national soft power. It is an important way for the country to go to the international development road as soon as possible. Therefore, in the era of vigorously advocating the development of overseas education, traditional education for foreign students also has many roles.

Carry forward the national traditional sports culture spirit. China has 5,000 years of heritage civilization and culture has a long history, in the history of the river in the accumulation and precipitation, including the philosophy of life. Such as tai chi, is the ancient movement of our body down. However, Taijiquan contains a wealth of cultural knowledge, hardness and softness, mutual integration. From the action of the essentials, posture and display the form and its play and play the power, are worth learning and reflection. From which we can experience the traditional cultural connotation of China's sports, and gradually establish a sense of identity towards our traditional culture, so as to better spread the traditional culture of the country to the rest of the world, so that they agree with China. So that the traditional Chinese sports culture to better carry out, spread out.

To enhance the status of national traditional sports culture. International student education is an internationalized, multi-level, multi-angle traditional national customs, traditional culture, knowledge and lifestyle integration education. In the process of learning in colleges and universities, students will be unknowingly affected by the local culture of infection and nurture, will subtle influence on the human nature of the habit, to enhance the identity of the local country and accept its traditional cultural connotation, which will Culture spread to the rest of the world, which is a national traditional culture spread to the rest of the world's opportunities for the world to understand and recognize China. Today, it is an era of vigorously advocating and developing the study abroad. It is the era of cultural integration and development. Our country should grasp the melody of the times and play the triumph of the times and use this opportunity to expand our international status and image.

Today's social information technology continues to develop and popularize, the development of internationalization will be the inevitable trend of the development of the times. International student education will be an important bridge to promote the integration of the times. Students can not only understand the traditional culture of their own knowledge, but also to understand the traditional foreign cultural knowledge, more conducive to promoting social integration. This will also be an important link for China to enter the international track, but also a key element of national prosperity and development. The education of foreign students is also of great significance to improve the educational level of our country, to adapt to the trend of internationalization, to strengthen exchanges and cooperation with the international community, to improve the level of education and improve competitiveness.

\section{The Method of Traditional Sports Culture Education for Foreign Students}

The goal of physical education curriculum is an important part of the whole PE curriculum design, which is the basis of PE curriculum evaluation and the main clue to the whole teaching process. Whether the goal of physical education curriculum can play an important role in physical education curriculum, the key is whether it meets the characteristics and needs of physical and mental 
development of students, whether it meets the development characteristics and needs of the discipline itself, and finally whether it can reflect the needs of society and Accepted. In the traditional sports culture courses of college students can develop the following specific teaching objectives.

From the reasonable arrangements, the principle of scientific set out to enhance the students' physical fitness, improve sports capacity and promotes the development of physical and mental health as the starting point. Such as the shuttlecock is widely circulated in our country, a long history of traditional national sports, is a set of skills, entertainment and fitness functions in a sports. It features a simple, easy-to-use feature that is well suited for being a project that exists in traditional sports culture courses. To convey the traditional sports culture knowledge and skills for the purpose of students to meet the traditional Chinese sports and other sports knowledge learning needs. To shuttlecock as an example, the shuttlecock sports skills to teach and social practice activities, both to meet the learning needs of students and students can better participate in the region's national fitness campaign. To cultivate students' interest in national traditional sports for the purpose of the same time, pay attention to the cultivation of individuality, traditional sports and traditional culture, national spirit closely linked by the training of students on the national traditional sports interest extended to the traditional culture of the nation Love.

Curriculum reform should be consistent with the development of disciplines and trends, and take the direction of comprehensive development of the road and the curriculum should follow the students to learn the law and physical development characteristics to be flexible and reasonable set. The main purpose of international students is to study and the purpose of our country to recruit foreign students is to expand our international influence. Therefore, the curriculum should not only consider the characteristics of the traditional Chinese sports and the characteristics of the traditional national sports curriculum, but also the actual situation of the school and the students' own conditions. In short, the course content should be set up in certain standards. The content of the traditional national sports curriculum of the international students should be basically the same as that of the ordinary national traditional sports content selection standard, but it must have its own specific standard. Before setting up the course content, we must first fully understand the characteristics of the traditional sports curriculum to be selected. Secondly, we should fully consider whether we meet the conditions and characteristics of the students, especially the physical and mental characteristics of the students and the needs of their development. Finally, but also learn from other curriculum content set up experience and relevant experts point of view, scientific and rational content of the course set.

Based on the above criteria, our country can also set up other courses with Chinese national characteristics for sports students, such as traditional guidance, health and other subjects, to expand the width of the traditional national sports culture. Traditional sports health is one of the three research directions of national traditional sports in colleges and universities, and it is a frontier academic field of traditional Chinese sports research. The curriculum of traditional sports health is the key to the reform of national traditional sports teaching. It plays an invaluable role in promoting the development of traditional sports in our country, carrying forward the traditional national health culture, strengthening students' physique, regulating physical and mental state and lifelong sports formation. With the attention of the education sector, many colleges and universities (including sports colleges and universities) have set up the national traditional sports department, and the establishment of the national traditional sports base, in some areas of folk projects have also been included in the teaching content. Physical education curriculum evaluation as an important content, not only reflects the student's learning effect and reveals the classroom teaching quality. The evaluation of national traditional sports curriculum mainly includes students 'technical evaluation, students' mental health, sports participation and social adaptation. It aims to examine students in a comprehensive and objective way.

\section{Conclusion}

National traditional sports culture as an important part of China's sports culture, is in the history of 
development and life practice gradually retain the essence, to its dregs developed. It is an effective way to inherit and carry forward the traditional culture of the nation by establishing the national traditional sports curriculum in colleges and universities. Excellent traditional culture only to be inherited, can withstand the test of history.

\section{Acknowledgements}

Study on the Influence of National Traditional Sports Culture on Medical Students in Colleges Xiang Cai Jiao Zhi [2015]54 15C0174

\section{References}

[1] Liu Yang, Wang Hui, Kong Fansheng. Foreign students why study abroad in China - based on the Beijing University of empirical research [J]. Higher Education Research, 2013 (05)

[2] Cui Jiang. Chinese traditional sports culture analysis [J]. Sports Culture Guide, 2005 (11)

[3] Huang Daqing, Yang Yintian, Xu Mingkui. On the differences in the connotation of the spirit of Chinese and Western sports culture [J]. Journal of Xi'an Institute of Physical Education, 2005 (03)

[4] Shi Hongru. Globalization under the background of the development of traditional Chinese sports culture [J]. Sports Culture Guide, 2004 (04)

[5] Gu Feng, Hu Shijun, Hu Yuhua. Comparative Study on Chinese Traditional Sports Culture and Western Sports Culture [J]. Journal of Anhui Sports Science and Technology. 2003 (04)

[6] Xie Huirong, Lu Chunlei, Yao Lei. Chinese traditional sports culture of the times [J]. Journal of Shandong Institute of Physical Education, 1997 (02) 